\title{
Influence of Spinneret Polarity in Needleless Electrospinning
}

\author{
Usman Ali ${ }^{1,2}$, Sarmad Aslam ${ }^{1}$, Haitao $\mathrm{Niu}^{2}$, Muhammad Bilal Qadir ${ }^{3}$, Tong Lin $^{2}$, Anwar ul Aleem ${ }^{1}$, Amir Abbas $^{1 * *}$ \\ ${ }^{1}$ College of Textile Engineering, BZU, Multan 60800, Pakistan \\ ${ }^{2}$ Institute for Frontier Materials, Deakin University, Geelong, VIC, 3216, Australia \\ ${ }^{3}$ Department of Material Engineering, National Textile University, Faisalabad 38000, Pakistan
}

Corresponding Author: Amir Abbas, amir.abbas@bzu.edu.pk

\begin{abstract}
Needleless electrospinning in recent years developed as a technique to produce polymeric nanofibres on large scale. This study was conducted to observe the influence of spinneret polarity on needleless electrospinning. Depending on the type of spinneret polarity, electrospinning led to different fibre morphology, productivity and areal density. The electric field profile in the electrospinning zone was analyzed by using finite element method. It was revealed that the intensity of electric field was higher in the part that was connected with a high voltage electrode. This could be the main reason of variances in fibre diameter, productivity and areal density.
\end{abstract}

\author{
ARTICLE HISTORY \\ Received: 04.12.2019 \\ Accepted: 22.02.2021
}

\section{KEYWORDS}

Spinneret, Electrode polarity, Sprocket wheel, Electric field

\section{INTRODUCTION}

Needleless electrospinning has now become the straight forward and cost effective way to produce nanofibres for industrial scale [1-3]. These spinning fibres possess unique properties such as high surface to volume ratio, excellent porosity and permeability, core-shell [4] and are capable to incorporate other nano particles into the fibres. Due to this distinctive combination of these characteristics, needleless electrospinning nanofibres have been used in assorted areas such as scaffolds [5, 6] energy devices [7], nanocomposites [8, 9]and filtrations [10-12].

In needleless electrospinning process, a polymer solution is poured into a Teflon bath. The Teflon bath has a metal electrode that is connected to a high voltage output of power supply and a metal collector is connected to the grounded electrode. A geometric shape also known as spinneret immersed in solution bath and due to its rotation it takes the solution upward. Spinning process take place when the electrostatic forces overcome the surface tension of solution and electrically charged numerous jets ejected from the top of spinneret [13]. Researchers have paid a lot of attention to optimize the geometry of spinning spinneret and invent spinneret of various shapes like cylinder [14-16], disk [17, 18], cone [19], spiral coil [20-22], plate edge [23], stepped pyramid stage [24], wire electrode [25], conical wire coil [26], umbellate nozzles[27] and flat spinneret [28]. Research has also been conducted to see the influence of solution properties [29] and processing parameters [24, 30] on the resulted nanofibres. Different attempts have also been made to make the fibres directly from the surface of solution known as free surface solution spinning [31, 32], bubble spinning [33] or foam spinning [34] . In 2014 Xin et al.[35] studied the effect of airflow and found that the structure and quality of needleless electrospinning nanofibres got improve by using the air flow along with the spinneret. In a recent study[13] a comparison between sprocket wheel and disk has been drawn. It was found that electric field is the main driving force to start the electrospinning. It was also found that spinneret that has large curvature will generate high electric field intensity regardless of the other parameters. Despite the fact that considerable research has been done to optimize the shape of spinneret, but there are also other factors such as the effect of electrode connections and areal density of resulted fibres still need to be explored.

In this study the effect of electrode polarity on needleless

To cite this article: Ali U, Aslam S, Niu H, Qadir MB, Lin T, Aleem A, Abbas A. 2021. Influence of Spinneret Polarity in Needleless Electrospinning. Tekstil ve Konfeksiyon, 31(1), 10-18. 
electrospinning has been studied. Sprocket wheel was used as a model spinneret. The electrode connections were compared in terms of electric field intensity, resulted fibre morphology, areal density and productivity under different parameters. It was found that the resulted fibres from the reversal electrode connection are coarser but have much higher areal density as compared to the normal electrode connection.

\section{EXPERIMENTAL}

\subsection{Materials, Methods and Characterization:}

Poly(vinyl alcohol) (PVA, $\left.\mathrm{M}_{\mathrm{w}}=186000\right)$ was obtained from Daejung chemicals and metal Co. Ltd and used as received. The poly vinyl alcohol solutions of various concentrations such as 7\%, 8\%, 9\%, and $10 \%$ were prepared by dissolving PVA in distilled water at $70^{\circ} \mathrm{C}$ and continuous stirring for $24 \mathrm{hrs}$.

The morphologies of resulted fibres were observed under scanning electron microscope (JCM-60000 plus NeoScope Benchtop SEM). Fibres diameters were measured by using image analysis software image-pro 6.5 based on the SEM images. The photographs of the deposited nanofibres were taken by using the digital camera Nikon 5100 and deposition area of fibres was also measured by using image-pro software 6.5. The electrospinning was carried out continuously for one hour and five measurements were taken for each condition. The weight of fibres was measured by using analytical balance (Excellence XS). SEM samples were prepared from ten different areas of resulted membrane and diameter of at least 100 fibres was measured to calculate the average fibre diameter. The electric field intensities were calculated by using infinite element method using the software COMSOL Multiphysics 5.0. Three-dimensional shape of spinneret was made by using solid works 2014 and then imported into COMSOL Multiphysics 5.0. All experiments were performed under standard atmospheric conditions temperature $25 \pm 5^{\circ} \mathrm{Cand}$ humidity $65 \pm 5 \%$.

The schematic diagram of a needleless electrospinning is shown in figure 1a. It comprises of a high voltage supply, Teflon bath, collector and sprocket wheel disk spinneret. The dimensions of sprocket wheel disk spinneret are as inside diameter $=50 \mathrm{~mm}$, outer diameter $=60 \mathrm{~mm}$ pitch $=$ $13.10 \mathrm{~mm}$ and thickness $5 \mathrm{~mm}$. Whereas the dimensions of collector covered with non-woven fabric are as length $\times$ width $\times$ thickness, $685 \times 635 \times 10 \mathrm{~mm}$. The spinneret was rotated by using a $12 \mathrm{v}$ DC motor. High voltage power supply purchased from Gamma high voltage research, Florida USA was used to study the effect of electrode connections on electrospinning process and resulted fibre morphology. The high voltage power supply has a positive high-voltage output and a ground return (model ES100P$5 \mathrm{~W})$. The center of collector and tip of spinneret was aligned so that nanofibres spinning from spinneret directly deposited onto the collector. Two electrode connections were made such as by connecting the positive terminal of high voltage supply to the metal electrode placed in the solution bath and grounded electrode to the collector as shown in the figure $1 \mathrm{~b}$. This connection was abbreviated as PHV-G. Second electrode connection can also be called as reverse connection was made by connecting positive terminal of high voltage supply to the collector and the ground electrode to the metal electrode placed in solution bath as shown in figure 1c. This connection was abbreviated as G-PHV.

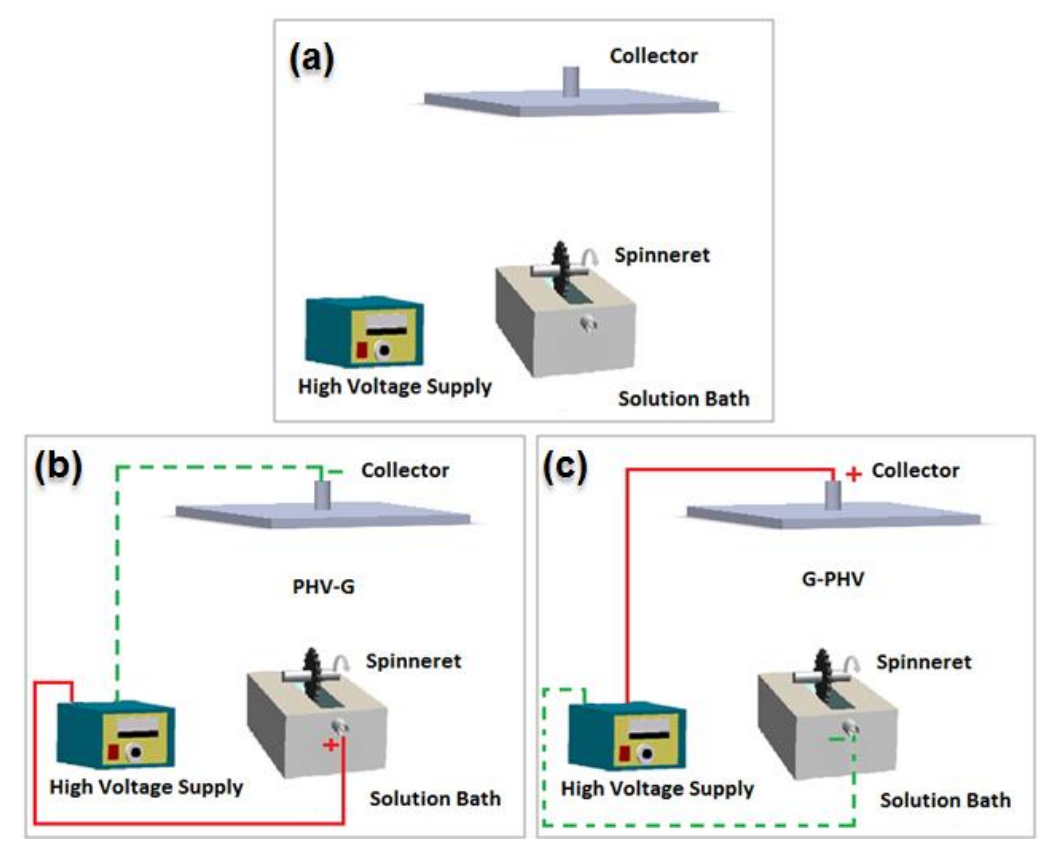

Figure 1. Representation of a) Basic needleless electrospinning mechanism, b) Electrode connection PHV-G and c) Electrode connection G-PHV respectively. 


\section{RESULTS AND DISCUSSION}

\subsection{Electrospinning and Electric field analysis}

Needleless electrospinning was carried out by dipping a small part of the spinneret sprocket wheel into Teflon bath containing polymer PVA solution. The sprocket wheel was rotated by a $12 \mathrm{v}$ DC power supply with a constant speed of 4 revolutions per minute. Due to rotation of sprocket wheel the immersed teeth of sprocket wheel brought the polymer solution to top position of sprocket wheel. When the applied voltage was high enough the electrostatic forces overcome the surface tension and polymeric jets are ejecting from the teeth of sprocket wheel. The ejected polymeric jets flew towards collector under the influence of electric field. Due to evaporation of solvent semi dry nanofibres collected on the collector. To understand the effect of electrode connections, electrospinning was carried out under both connections by keeping all the other parameters constant. Figure 2 shows the photographs of the ongoing spinning process, deposited nanofibrous membrane and SEM images of the resulted nanofibres as a result of electrode connections PHV-G and G-PHV respectively. It could be seen that much longer and straight polymer Taylor cones are generating from G-PHV electrode connection as compare to the PHV-G electrode connection. It was also meaningful to note that nanofibres obtained due to electrode connection PHV-G deposited on large surface area and have finer fibre diameters as compared to the fibres produced from G-PHV electrode connection.

The effect of spinneret polarity on the electric field profiles obtained from both connections were studied by finite element method with COMSOL Multiphysics 5.0 by keeping the same collecting distance $13 \mathrm{~cm}$. Figure $3 \mathrm{a}$ and $3 \mathrm{~d}$ shows the electric field profile around the spinneret and collector due to electrode connections PHV-G and GPHVrespectively. It could be seen that in electrode connection PHV-G, electric field profile is more concentrated around the spinneret whereas in electrode connection G-PHV it is more concentrated around collector. To better understand the change of electric potential in the electrospinning zone two cut lines were drawn in the electrospinning zone and electric potential was measured along cutline. First cutline $40 \mathrm{~cm}$ was drawn perpendicular to sprocket edge and second from the top position of sprocket wheel to the edge of collector and electric potential was measured for both connections PHV$\mathrm{G}$ and G-PHV under various applied voltages as shown in figure $3 b-c$ and $3 e-f$ respectively. From these graphs it is clearly seen that regardless of the applied voltage electric potential will be more concentrated on the electrode that is connected to the positive terminal of high voltage power supply and vice versa. That could be the main reason that fibre produced from the electrode connection PHV-G are slightly finer than the fibres produced from the electrode connection G-PHV. On the other side regarding to deposition surface area, in electrode connection PHV-G as the distance increases from the spinneret to collector the electric potential become weaker resulting the deposition of fibres on large surface area, whereas on the other side in GPHV electrode connection electric potential is much stronger around the collector and hence the polymer jets ejecting from the spinneret surface travels straight towards the collector and deposited on the less area of collector.
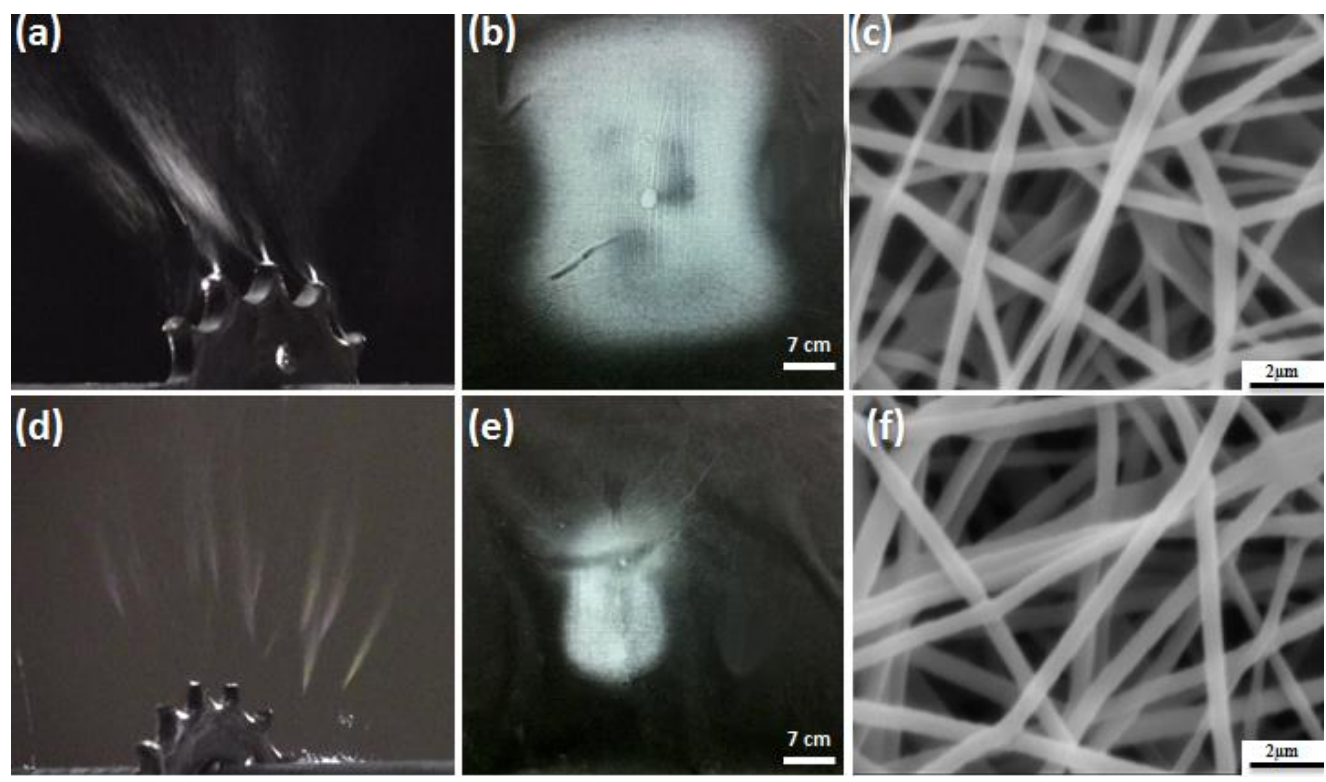

Figure 2. Representation of the a-c) photograph of spinning process, deposited nanofibres and SEM image of resulted nanofibres as a result of electrode connection PHV-G and d-f) photograph of spinning process, deposited nanofibres membrane and SEM image of resulted nanofibres as a result of electrode connection G-PHV respectively. 
(a)

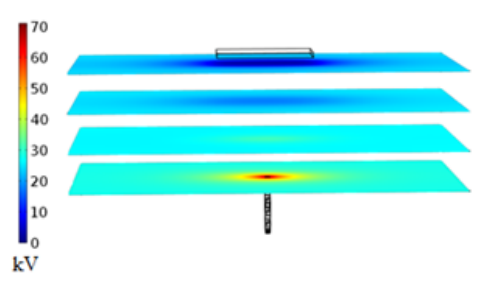

(d)

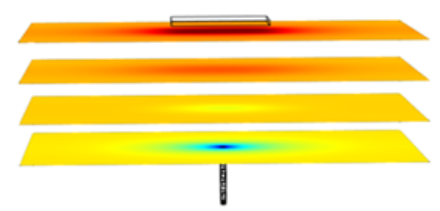

(b)

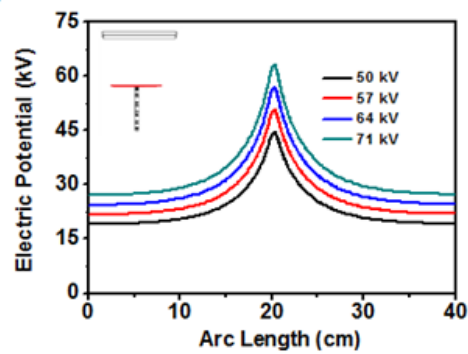

(e)

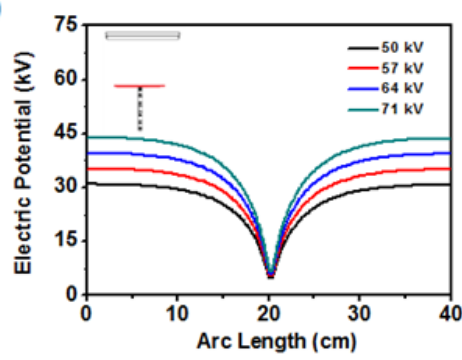

(c)

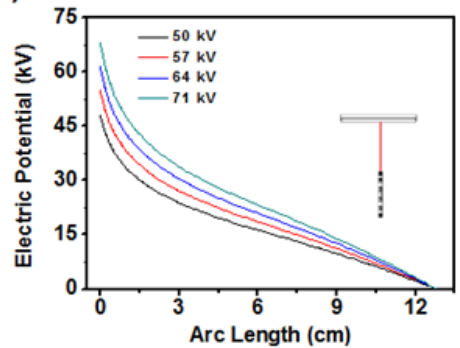

(f)

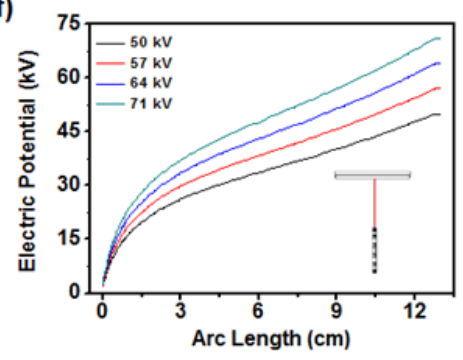

Figure 3. Representation of the electric potential a-c) profile around the spinneret and collector, perpendicular to spinneretcenter and parallel to spinneret edgeas a result of electrode connection PHV-G and d-f) profile around the spinneret and collector, perpendicular along the spinneret and parallel to the spinneret as a result of electrode connection G-PHV respectively.

Since in electrospinning it is a well-known that the morphology and productivity of resulted nanofibres is greatly affected by the process and solution parameters. Therefore, in the following sections the influence of their parameters with respect to the spinneret polarity will be investigated and discussed in details.

\subsection{Influence of applied voltage}

To see the influence of applied voltage on electrode connections the electrospinning was carried out by varying the magnitude of applied voltage and keeping all the other parameters constant such as solution concentration $8 \%$ (w/v) and collecting distance $13 \mathrm{~cm}$. It was noted that in case of G-PHV electrode connection no jet was formed when the magnitude of applied voltage was less than $44 \mathrm{kV}$. Further increasing the applied voltage from this critical voltage resulted in the formation of jets from the teeth of sprocket wheel, whereas the critical voltage for the PHV-G electrode connection was found to be $38 \mathrm{kV}$. Further increasing the applied voltage to $50 \mathrm{kV}$ it was found that numerous jets are ejecting from the surface of spinneret for both electrode connections. To observe the influence of applied voltage on fibre morphology, productivity, surface area and areal density the applied voltage was changed from $50 \mathrm{kV}$ to $70 \mathrm{kV}$ by keeping all the other parameters constants. Figure 4 shows the SEM images of nanofibres produced from both the electrode connections as a change of applied voltage. The fibres obtained as a result of PHV$\mathrm{G}$ electrode connection are slightly finer than from fibres obtained as a result of G-PHV electrode connection.
Figure 5a shows the influence of applied voltage on fibre diameter and deposited surface area resulted from both electrode connections PHV-G and G-PHV respectively. It could be seen that with the increase in applied voltage diameter of individual fibres decreased and deposited surface area increased significantly for both connections. However, the fibres obtained from electrode connection PHV-G are finer and deposited on much higher surface area as compared to G-PHV electrode connection. As the applied voltage increased from $50 \mathrm{kV}$ to $71 \mathrm{kV}$, the average fibre diameter decreased from $425.64 \pm 122.58 \mathrm{~nm}$ to 285.3 $\pm 48.98 \mathrm{~nm}$ and surface area increased from $685.09 \mathrm{~cm}^{2}$ to $1124.97 \mathrm{~cm}^{2}$ for PHV-G electrode connection whereas the average fibre diameter decreased from $462.09 \pm 101.81 \mathrm{~nm}$ to $315.26 \pm 81.64 \mathrm{~nm}$ and surface area increased from $205.15 \mathrm{~cm}^{2}$ to $425.19 \mathrm{~cm}^{2}$ for G-PHV electrode connection.

The fibre productivity and the areal density of the resulted nanofibres membrane as a result of applied voltage is shown in figure $5 \mathrm{~b}$. It could be seen that productivity and areal density of nanofibrousmembrane increased with increasing the applied voltage for both electrode connections. The areal density of nanofibrous membrane obtained as result of PHV-G electrode connection is much thinner than the areal density of nanofibrous membrane obtained from G-PHV electrode connection, nevertheless the production of $\mathrm{PHV}-\mathrm{G}$ electrode connection is slightly higher than the G-PHV electrode connection. This is because the fibre obtained from PHV-G electrode connection are deposited on much large surface area and resulted in thinner linear density as compared to G-PHV electrode connection. As applied voltage was increased from $50 \mathrm{kV}$ to $70 \mathrm{kV}$, the fibre productivity and areal 
density increased from $840 \mathrm{mgh}^{-1}$ to $3580 \mathrm{mg} \mathrm{h}^{-1}$ and 1.22 $\mathrm{mg} \mathrm{cm}^{-2}$ to $3.18 \mathrm{mg} \mathrm{cm}-2$ for PHV-G electrode connection whereas fibre productivity and areal density increased from
$570 \mathrm{mg} \mathrm{h}^{-1}$ to $3240 \mathrm{mg} \mathrm{h}^{-1}$ and $2.7 \mathrm{mg} \mathrm{cm}^{-2}$ to $7.6 \mathrm{mg} \mathrm{cm}^{-2}$ for G-PHV electrode connection respectively.

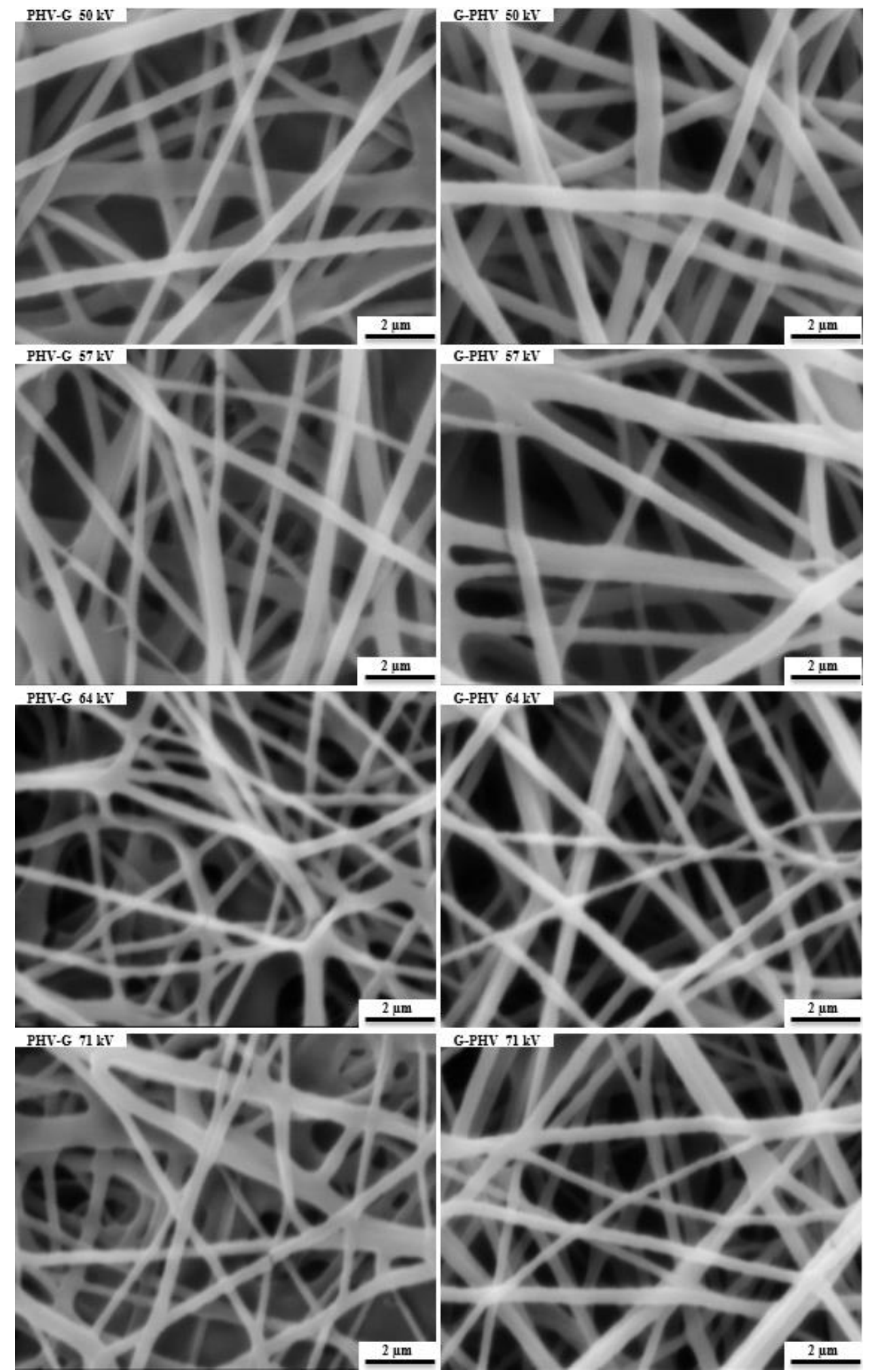

Figure 4. SEM images of resulted nanofibres at various applied voltages as a result of electrode connections PHV-G and G-PHV respectively (Collecting distance $=13 \mathrm{~cm}$, polymer concentration $=8 \% \mathrm{w} / \mathrm{v})$. 

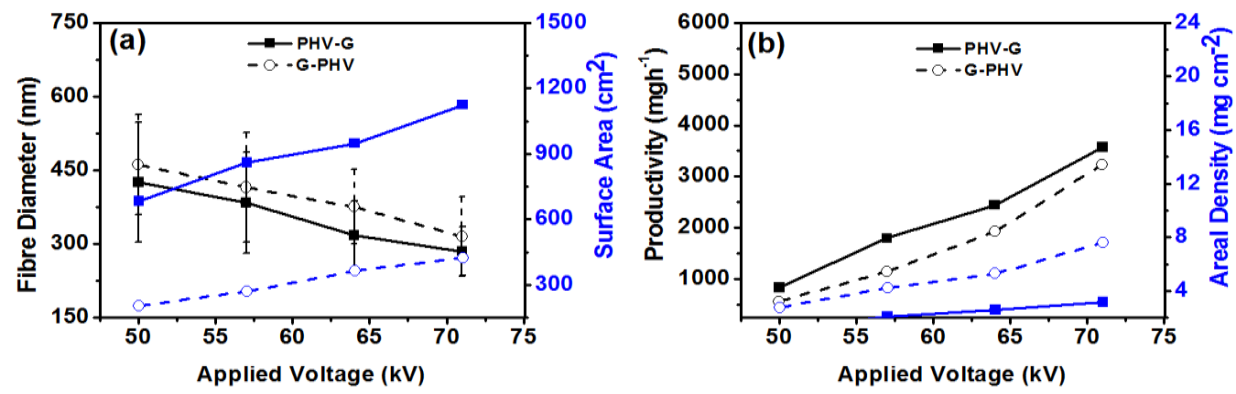

Figure 5. Influence of applied voltage on a) fibre diameter and surface area of resulted nanofibrous membrane and b) fibre productivity and areal density of resulted nanofibrous membrane as a result of electrode connections PHV-G and G-PHV respectively $($ Collecting distance $=13 \mathrm{~cm}$ and polymer concentration $=8 \% \mathrm{w} / \mathrm{v})$.

\subsection{Influence of polymer concentration}

Effect of polymer concentration on fibre morphology, surface area, productivity and areal density due to change of electrode connections in needleless electrospinning was carried out by varying the concentration from $7 \%(\mathrm{w} / \mathrm{v})$ to $10 \%(\mathrm{w} / \mathrm{v})$ and by keeping all the other parameters constants such as applied voltage $57 \mathrm{kV}$ and collecting distance $13 \mathrm{~cm}$ respectively. Figure 6 shows the SEM images of nanofibres produced from both the electrode connections as a result of change in solution concentration. The fibres obtained from PHV-G electrode connection are slightly finer than the fibres obtained from the G-PHV electrode connection.

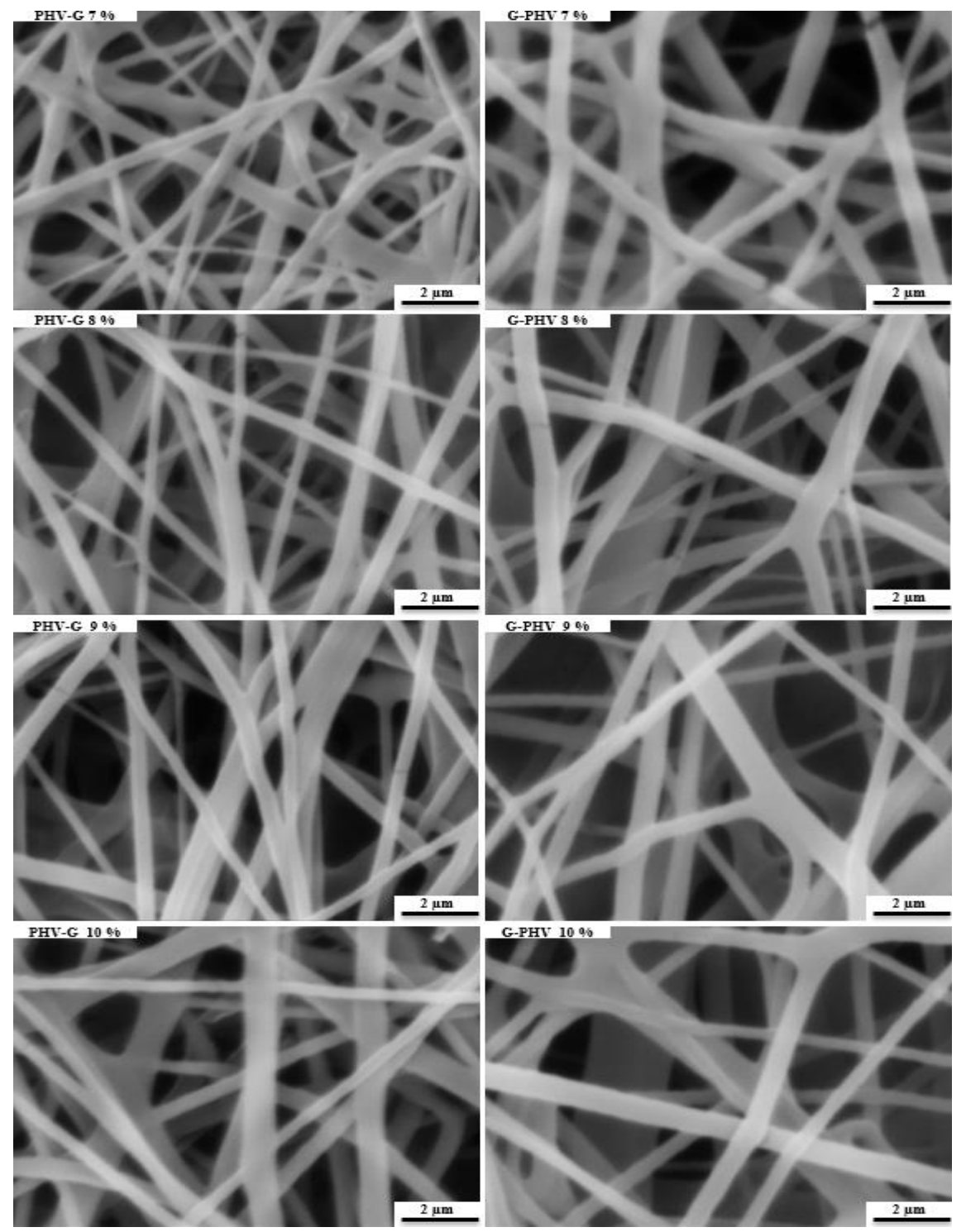

Figure 6. SEM images of resulted nanofibres at various solution concentrations as a result of electrode connections PHV-G and G-PHV respectively (Collecting distance $=13 \mathrm{~cm}$, applied voltage $=57 \mathrm{kV})$. 
Figure 7a shows the influence of polymer solution concentration on fibre diameter and deposited surface area resulted from both electrode connections PHV-G and GPHV respectively. It could be seen that the individual fibre diameter and surface area increased with the increase of polymer solution concentration for both electrode connections. Neverthelessfibrediameter obtained from the PHV-G electrode connection are slightly finer than the fibre diameter obtained from G-PHV electrode connection. As the polymer concentration increased from $7 \%(\mathrm{w} / \mathrm{v})$ to $8 \%(\mathrm{w} / \mathrm{v})$, the average fibre diameter increased from 310.73 $\pm 73.48 \mathrm{~nm}$ to $464.61 \pm 134.89 \mathrm{~nm}$ and surface area increased from $814.26 \mathrm{~cm}^{-2}$ to $934.27 \mathrm{~cm}^{-2}$ for PHV-G electrode connection whereas the average fibre diameter increased from $405.62 \pm 98.25 \mathrm{~nm}$ to $515.98 \pm 105.12 \mathrm{~nm}$ and surface area increased from $234.19 \mathrm{~cm}^{-2}$ to $315.12 \mathrm{~cm}^{-}$ ${ }^{2}$ for G-PHV electrode connection respectively.

Figure $7 \mathrm{~b}$ shows the influence of solution concentration on fibre productivity and areal density as a result of both electrode connections. It could be seen that productivity and areal density of nanofibrous membranes increased with increasing the solution concentration for both electrode connections. As the polymer concentration was increased from $7 \%(\mathrm{w} / \mathrm{v})$ to $8 \%(\mathrm{w} / \mathrm{v})$, the fibre productivity and areal density increased from $2100 \mathrm{mg} \mathrm{h}^{-1}$ to $5240 \mathrm{mg} \mathrm{h}^{-1}$ and 2.57 $\mathrm{mg} \mathrm{cm} \mathrm{cm}^{-2}$ to $5.60 \mathrm{mg} \mathrm{cm}^{-2}$ for PHV-G electrode connection whereas fibre productivity and real density increased from $1300 \mathrm{mg} \mathrm{h}^{-1}$ to $4450 \mathrm{mg} \mathrm{h}^{-1}$ and $5.5 \mathrm{mg} \mathrm{cm}^{-2}$ to $14.12 \mathrm{mg}$ $\mathrm{cm}^{-2}$ for G-PHV electrode connection respectively.

\subsection{Influence of collecting distance}

Collecting distance also influence the fibre diameter, surface area, productivity and real density. To see this influence the collecting distance was varied from $11 \mathrm{~cm}$ to
$15 \mathrm{~cm}$ by keeping all the other parameters constant such as applied voltage $57 \mathrm{kV}$ and solution concentration $8 \%(\mathrm{w} / \mathrm{v})$. Figure 8 shows the SEM images of nanofibres obtained as a result of varying collecting distance. It could be seen that the fibres diameter obtained from PHV-G electrode connection are slightly finer than the fibres obtained from G-PHV electrode connection as result of varying collecting distance.

Figure 9a shows the graphically representation of fibre diameter and deposited surface area as a result of both electrode connections PHV-G and G-PHV respectively. It could be seen that fibre diameter decrease slightly as the collecting distance increased nevertheless that there is a dramatically increase in fibre surface area for both electrode connections. As the collecting distance was increase from $11 \mathrm{~cm}$ to $15 \mathrm{~cm}$ the average fibre diameter decreased from $402.98 \pm 78.03 \mathrm{~nm}$ to $356.47 \pm 85.83 \mathrm{~nm}$ and surface area increased from $778.12 \mathrm{~cm}^{-2}$ to $1015.67 \mathrm{~cm}^{-}$ 2 for PHV-G electrode connection, whereas the average fibre diameter decreased from $454.43 \pm 98.47 \mathrm{~nm}$ to 388.25 $\pm 56.12 \mathrm{~nm}$ and surface area increased from $215.12 \mathrm{~cm}^{-2}$ to $384.95 \mathrm{~cm}^{-2}$ for G-PHV electrode connection respectively.

The fibre productivity and areal density as the influence of collecting distance are shown in figure 9b. It could be seen that the fibre productivity and areal density both decreased with increasing the collecting distance for both electrode connections. As the collecting distance was increased from $11 \mathrm{~cm}$ to $15 \mathrm{~cm}$ the fibre productivity and areal density decreased from $2845 \mathrm{mg} \mathrm{h}^{-1}$ to $2615 \mathrm{mg} \mathrm{h}^{-1}$ and from 3.65 $\mathrm{mg} \mathrm{cm}^{-2}$ to $2.57 \mathrm{mg} \mathrm{cm}^{-2}$ for PHV-G electrode connection. Whereas the fibre productivity and areal density decreased from $2601 \mathrm{mg} \mathrm{h}^{-1}$ to $1995 \mathrm{mg} \mathrm{h}^{-1}$ and from $12.08 \mathrm{mg} \mathrm{cm}^{-2}$ to $5.19 \mathrm{mg} \mathrm{cm}^{-2}$ for G-PHV electrode connection respectively.
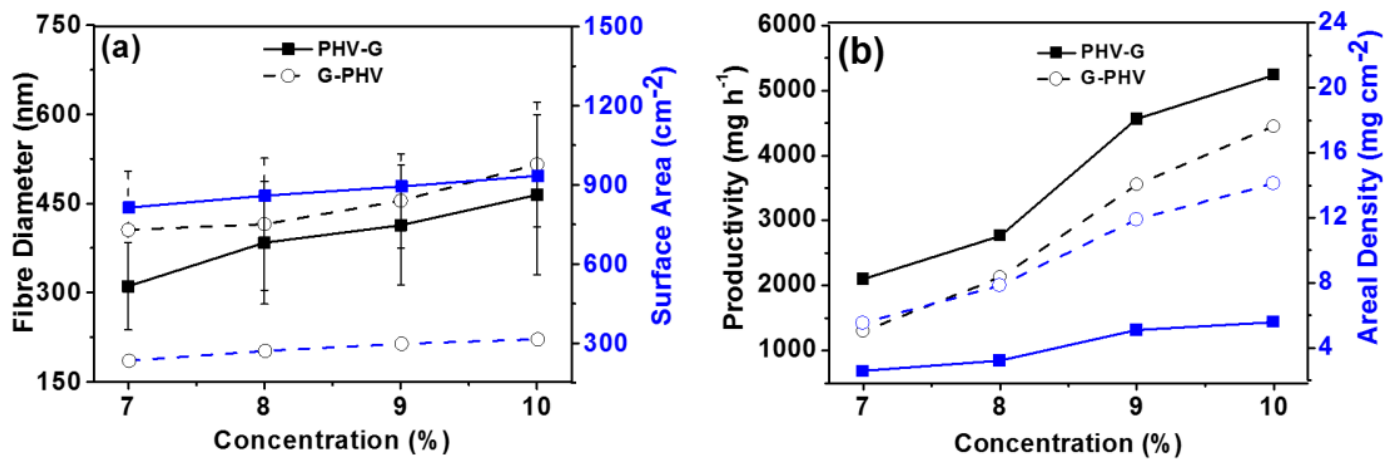

Figure 7. Influence of polymer concentration on a) fibre diameter and surface area of resulted nanofibrous membrane and b) fibre productivity and areal density of resulted nanofibrous membrane as a result of electrode connections PHV-G and G-PHV respectively (Collecting distance $=13 \mathrm{~cm}$, applied voltage $=57 \mathrm{kV})$. 


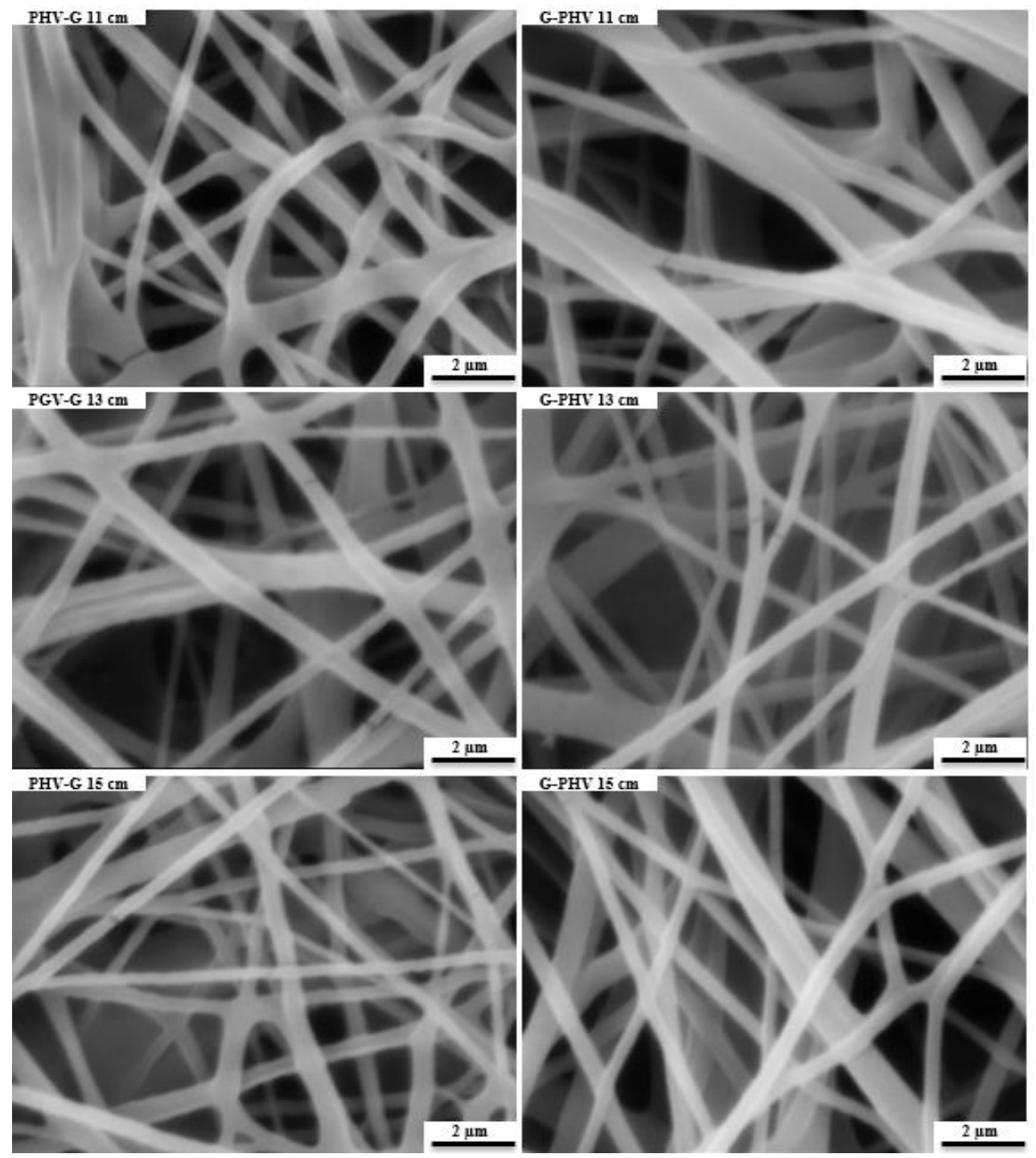

Figure 8. SEM images of resulted nanofibres at various spinning distances as a result of electrode connections PHV-G and G-PHV respectively (Applied voltage $=57 \mathrm{kV}$, Polymer concentration $=8 \% \mathrm{w} / \mathrm{v})$.
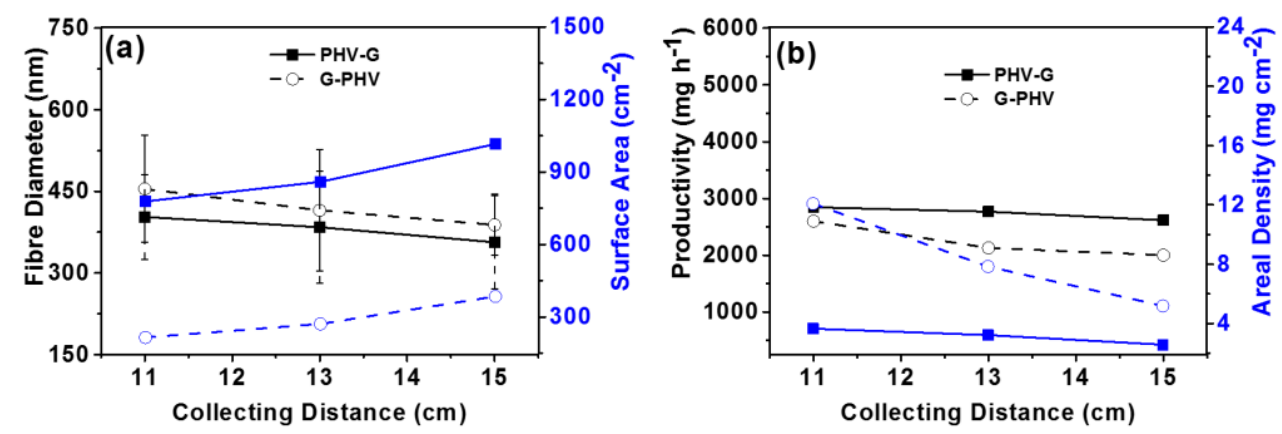

Figure 9. Influence of collecting distance on a) fibre diameter and surface area of resulted nanofibrousmembrane and b) fibre productivity and areal density of resulted nanofibrousmembrane as a result of electrode connections PHV-G and G-PHV respectively ( Applied voltage $=57 \mathrm{kV}$, polymer concentration $=8 \mathrm{wt} \%$ ).

\section{CONCLUSION}

In this study it was proved that needleless electrospinning can also be carried out by reversing the electrode connections. Both normal PHV-G and reverse G-PHV electrode connections were compared in terms of critical voltage, electric potential around the spinneret and collector, fibre morphology, deposited surface area, fibre productivity and areal density of resulted nanofibrousmembranes. Higher potential difference is located around electrode that is connected to positive terminal of high voltage supply. Although the fibre produced from the reverse electrode connection G-PHV are 
coarser and have less production than the fibres produced from normal electrode connection but they deposited on less surface area and resulted in higher areal density nanofibrous membranes as compared to PHV-G electrode

\section{REFERENCES}

1. Ramakrishnan R, Gimbun J, Samsuri F, Narayanamurthy V, Gajendran N, Sudha Lakshmi Y and et al. 2016. Needleless Electrospinning Technology - An Entrepreneurial Perspective, Indian Journal of Science and Technology, 9(15):1-11

2. Persano L, Camposeo A, Tekmen C, Pisignano D. 2013. Industrial Upscaling of Electrospinning and Applications of Polymer Nanofibres: A Review, Macromolecular Materials and Engineering, 298, 504-520.

3. Zhou FL, Gong RH, Porat I. 2009. Mass production of nanofibre assemblies by electrostatic spinning, Polymer International, 58, 331342 .

4. Jiang G, Qin X. 2014. An improved free surface electrospinning for high throughput manufacturing of core-shell nanofibres, Materials Letters, 128, 259-262

5. Cipitria A, Skelton A, Dargaville TR, Dalton PD, Hutmacher DW. 2011 Design, fabrication and characterization of PCL electrospun scaffoldsa review, Journal of Materials Chemistry, 21, 9419-9453

6. Dubský M, Kubinová Š, Širc J, Voska L, Zajíček R, Zajícová A, et al. 2012. Nanofibres prepared by needleless electrospinning technology as scaffolds for wound healing, Journal of Materials Science: Materials in Medicine, 23, 931-941.

7. Fang J, Niu H, Wang H, Wang X, and Lin T, 2013. Enhanced mechanical energy harvesting using needleless electrospun poly(vinylidene fluoride) nanofibre webs, Energy \& Environmental Science, 6, 2196-2202.

8. Brettmann BK, Tsang S, Forward KM, Rutledge GC, Myerson AS, Trout BL. 2012. Free Surface Electrospinning of Fibres Containing Microparticles, Langmuir, 28, 9714-9721.

9. Kostakova E, Meszaros L, Gregr J, 2009. Composite nanofibres produced by modified needleless electrospinning, Materials Letters, 63 , 2419-2422.

10. Li X, Zhang Y, Li H, Chen H, Ding Y, Yang W, 2014. Effect of oriented fibre membrane fabricated via needleless melt electrospinning on water filtration efficiency, Desalination, 344, 266-273.

11. Li H, Wu W, Bubakir MM, Chen H, Zhong X, Liu Z, et al. 2014, Polypropylene fibres fabricated via a needleless melt-electrospinning device for marine oil-spill cleanup, Journal of Applied Polymer Science, 131. $40080(1-9)$

12. Li X, Yang W, Li H, Wang Y, Bubakir MM, Ding Y, et al. 2015. Water filtration properties of novel composite membranes combining solution electrospinning and needleless melt electrospinning methods, Journal of Applied Polymer Science, 132(10), 41601(1-8)

13. Ali U, Niu H, Aslam S, Jabbar A, Rajput AW, Lin T. 2017. Needleless electrospinning using sprocket wheel disk spinneret, Journal of Materials Science, 52, 7567-7577.

14. Huang X, Wu D, Zhu Y, and Sun D, 2007. Needleless electrospinning of multiple nanofibres, in 2007 7th IEEE International Conference on Nanotechnology - IEEE-NANO 2007, Proceedings, Hong Kong, 823826.

15. Sinha M, Das B, Mishra R, Ranjan A, Srivastava A, Saxena A, 2014. Study of electrospun polycarbosilane (PCS) nanofibrousweb by needleless technique, Fashion and Textiles, 1:2, 1-14.

16. Jirsak O, Sysel P, Sanetrnik F, Hruza J, Chaloupek J, 2010. Polyamic acid nanofibres produced by needleless electrospinning, J. Nanomaterials, 1-6.

17. Li D, Wu T, He N, Wang J, Chen W, He L, et al. 2014. Threedimensional polycaprolactone scaffold via needleless electrospinning connection nanofibrous membranes. The reverse electrode connection could be used to produce denser nanofibrous membranes for better filtration applications.

promotes cell proliferation and infiltration, Colloids and Surfaces B: Biointerfaces, 121, 432-443.

18. Huang C, Niu H, Wu J, Ke Q, Mo X, Lin T. 2012. Needleless electrospinning of polystyrene fibres with an oriented surface line texture, J. Nanomaterials, ol. 2012, 1-7.

19. Lu B, Wang Y, Liu Y, Duan H, Zhou J, Zhang Z, et al. 2010, Superhigh-Throughput Needleless Electrospinning Using a Rotary Cone as Spinneret, Small, 6, 1612-1616.

20. Wang X, Niu H, Wang X, Lin T. 2012. Needleless electrospinning of uniform nanofibres using spiral coil spinnerets, J. Nanomaterials, 2012, $1-9$.

21. Wang X, Wang X, Lin T, 2012. Electric field analysis of spinneret design for needleless electrospinning of nanofibres, Journal of Materials Research, 27, 3013-3019.

22. Han W, Nurwaha D, Li C, Wang X. 2014. Free surface electrospun fibres: The combined effect of processing parameters, Polymer Engineering \& Science, 54, 189-197.

23. Thoppey NM, Bochinski JR, Clarke LI, Gorga RE. 2010. Unconfined fluid electrospun into high quality nanofibres from a plate edge, Polymer, 51, 4928-4936.

24. Jiang G, Zhang S, Qin X. 2016. Effect of processing parameters on free surface electrospinning from a stepped pyramid stage, Journal of Industrial Textiles, 45(4) 483-494

25. Forward KM, Rutledge GC. 2012. Free surface electrospinning from a wire electrode, Chemical Engineering Journal, vol. 183, 492-503.

26. Wang X, Niu H, Lin T, Wang X, 2009. Needleless electrospinning of nanofibres with a conical wire coil, Polymer Engineering \& Science, 49, 1582-1586.

27. Li H, Chen H, Zhong X, Wu W, Ding Y, Yang W, 2014. Interjet distance in needleless melt differential electrospinning with umbellate nozzles, Journal of Applied Polymer Science, 40515 (1- 8)

28. Zhou FL, Gong RH, Porat I, 2009. Polymeric nanofibres via flat spinneret electrospinning,Polymer Engineering \& Science, 49, 2475 2481 .

29. Cengiz F, Dao TA, Jirsak O. 2010. Influence of solution properties on the roller electrospinning of poly(vinyl alcohol), Polymer Engineering \& Science, 50, 936-943.

30. Wang X, Xu W. 2012. Effect of experimental parameters on needleless electrospinning from a conical wire coil, Journal of Applied Polymer Science, 123, 3703-3709.

31. Miloh T, Spivak B, Yarin AL. 2009. Needleless electrospinning Electrically driven instability and multiple jetting from the free surface of a spherical liquid layer, Journal of Applied Physics, 106, 114910

32. Yarin AL, Zussman E. 2004. Upward needleless electrospinning of multiple nanofibres, Polymer, 45, 2977-2980.

33. He JH, Liu Y, Xu L, Yu JY, Sun G. 2008. BioMimic fabrication of electrospun nanofibres with high-throughput, Chaos, Solitons \& Fractals, 37, 643-651

34. Higham AK, Tang C, Landry AM, Pridgeon MC, Lee EM, Andrady AL, et al. 2014. Foam electrospinning: A multiple jet, needle-less process for nanofibre production, AIChE Journal, 60, 1355-1364.

35. Wang $X$, Lin T, Wang X. 2015. Use of airflow to improve the nanofibrousstructure and quality of nanofibres from needleless electrospinning, Journal of Industrial Textiles. 45(2), 310-320 